\title{
Science and Time: Cognition and Human Development
}

$\mathrm{T}$ Time has been always a great allied of science. Even considering the complexity of its definition, rarely consensual, time is essential aspect to the refinement and evolution of science, which pursues to understand nature and man throughout the dynamic of the historical transformations.

The first step towards Science comes from ancient Greece, where philosophers started to explain world and human life in a different way, not more exclusively based in divine causes or mythology. Time went further and gave rise to a multiplicity of epistemological paradigms, which would concern to the physical world as well to the internal processes of individuals capable to perceive and interpret reality. When Psychology began to be established in eighteenth century, it received influences from different fields of science and philosophy and, nowadays, regardless of the differences between approaches, there is a unitary thought that psychology is an interdisciplinary science.

One of the most important areas that have contributed to Psychology is Neuroscience, which has helped to expand the understanding of the human being in its social, cultural and biological aspects. In last decades, advances in neuroscience are allowed, for example, by means of neuroimaging techniques, to observe in vivo the brain correlates of mental functioning. Presently, we can see that different subareas of psychology have established a close relationship with neurosciences, such as neuropsychology, experimental psychology, basic psychological processes, clinical psychology and social psychology.

In order to integrate cognitive, social, neuropsychological, and chronobiological perpectives on human development, the Cognitive and Behavioral Neuroscience Research Group, coordenated by Professor Katie Almondes of the Department of Psychology and Professor Antonio Pereira of the Brain Institute of the Federal University of the Rio Grande do Norte, organized the First Meeting on Cognitive and Behavioral Neuroscience, which had the guiding theme "Neuroscience and Human Development: new perspectives on cognitive processes". The event was held in Natal/RN in 2011 and bring together researchers of differents parts of Brasil interested in understand cognitive and behavioral aspects of human behavior.

The idea for the elaboration of the present dossier was bring to light from this meeting. Here, we intend to present to the scientific community some of the work developed by the groups that took part in the event and followed colaborating in research, namely the Cognitive and Behavioral Neuroscience Research
Group of the Federal University of Rio Grande do Norte, which was the proponent of the event; the Laboratory of Perception, Neuroscience and Behavior (LPNec), coordinated by Professor Natanael Antonio dos Santo of the Federal University of Paraíba, the Laboratory of Cognitive Sciences and Human Perception (LACOP), coordinated by Professor Nelson Torro Alves at the Federal University of Paraíba; the Integrated Laboratory of Neuropsychology (LINEU), coordinated by Professor Leandro Fernandes Malloy-Diniz of the Federal University of Minas Gerais. The meeting was supported by Brazilian Society of Neuropsychology, represented by the president Professor Leandro Fernandes Malloy-Diniz, who is our partner.

The proposal of the dossier and the selected papers were approved by the technical and ethical regulamentions of the Journal Estudos de Psicologia. The volume includes research topics on memory, visual perception, attention, perception of emotions, executive functions, sleep and decision making. Despite of the diversity of subject, the dossier gathers essentially works in Cognitive Neuroscience, which seeks to understand the relation between mental processes and the functioning of the nervous system.

We also take the opportunity to announce the release of the Graduate Program in Cognitive Neuroscience and Behaviour (PPGNeC) in the Federal University of Paraíba (UFPB), which was recently approved by the Coordenação de Aperfeiçoamento de Pessoal de Nível Superior (CAPES). The Graduate Program in Cognitive Neuroscience and Behaviour (UFPB) begins with the academic master degree in 2013 and will be coordinated by Professor Natanael Antonio dos Santos. The structure of the program includes the participation of nine teachers, seven laboratories, five departments and two centers, the Center of Humanities and Arts and the Center of Health Sciences of the Federal University of Paraíba. The PPGNeC has two research lines: (1) Psychobiology: Basic Psychological Processes and Neuropsychology; and (2) Cognitive Neuroscience Preclinical and Clinical. The PPGNeC aimed to strength teaching in Basic Psychological Processes (a subfield of psychology with scarce human resources in Brazil) and to develop a graduate training committed to innovation, interdisciplinarity and social inclusion, considering the multiplicity of methodological and theoretical approaches of neuroscience.

We hope that this dossier can contribute to the field of Cognitive Neuroscience and Basic Psychological Processes as well as to the technological development of Psychology. 